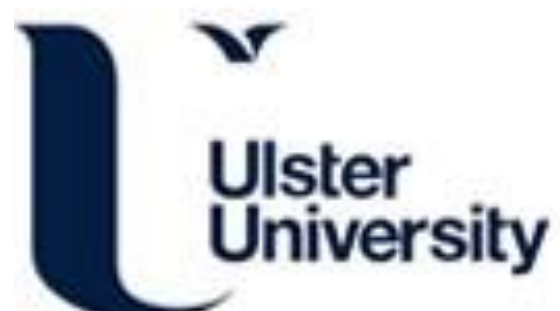

\section{Social workers' perceptions of restorative approaches with families in cases of elder abuse: a qualitative study}

Kirk, C. A., Killick, C., Mcallister, A., \& Taylor, B. (2019). Social workers' perceptions of restorative approaches with families in cases of elder abuse: a qualitative study. Journal of Adult Protection, 21(3), $190-200$. https://doi.org/10.1108/JAP-12-2018-0029

Link to publication record in Ulster University Research Portal

Published in:

Journal of Adult Protection

Publication Status:

Published (in print/issue): 30/05/2019

DOI:

10.1108/JAP-12-2018-0029

\section{Document Version}

Author Accepted version

\section{General rights}

Copyright for the publications made accessible via Ulster University's Research Portal is retained by the author(s) and / or other copyright owners and it is a condition of accessing these publications that users recognise and abide by the legal requirements associated with these rights.

\section{Take down policy}

The Research Portal is Ulster University's institutional repository that provides access to Ulster's research outputs. Every effort has been made to ensure that content in the Research Portal does not infringe any person's rights, or applicable UK laws. If you discover content in the Research Portal that you believe breaches copyright or violates any law, please contact pure-support@ulster.ac.uk. 


\section{Ulster}

\section{Social Worker's Perceptions of Restorative Approaches with Families in Cases of Elder Abuse: A Qualitative Study}

Cite as: Kirk CA, Killick C, McAllister A \& Taylor BJ (2019) Social workers perceptions of restorative approaches with families in cases of elder abuse: a qualitative study. The Journal of Adult Protection, 21(3), 190-200.

https://doi.org/10.1108/JAP-12-2018-0029 (published 30 May 2019)

\section{Published in:}

The Journal of Adult Protection,

\section{Document Version:}

Received Apr 2019, Accepted 30 May 2019, Published online: 08 Jun 2019

\section{Link to Ulster University Pure resource}

https://pure.ulster.ac.uk/en/persons/campbell-killick/publications/

\section{Publisher rights}

Copyright 2019 The Authors. This work is made available online in accordance with the publisher's policies. Please refer to any applicable terms of use of the publisher.

\section{Copyright}

Copyright for the publications made accessible via the Ulster University Pure resource is retained by the author(s) and / or other copyright owners and it is a condition of accessing these publications that users recognise and abide by the legal requirements associated with these rights. 
Social Worker's Perceptions of Restorative Approaches with Families in Cases of Elder Abuse: A Qualitative Study

Carole Kirk

Northern Health and Social Care Trust

Carole.Kirk@northerntrust.hscni.net

Campbell Killick

University of Ulster

c.killick@ulster.ac.uk

Anne McAllister

Northern Health and Social Care Trust

anne.mcallister@northerntrust.hscni.net

\author{
Brian Taylor \\ Ulster University \\ bj.taylor@ulster.ac.uk
}

Cite as: Kirk CA, Killick C, McAllister A \& Taylor BJ (2019) Social workers perceptions of restorative approaches with families in cases of elder abuse: a qualitative study. The Journal of Adult Protection, 21(3), 190-200. https://doi.org/10.1108/JAP-12-2018-0029 (published 30 May 2019)

\title{
Abstract
}

Purpose of this paper

This qualitative study explored professional perspectives on restorative approaches with families in elder abuse cases.

\section{Design, methodology and approach}

Data was gathered from 37 social workers in statutory and voluntary organisations through nine focus group sessions in one region of Northern Ireland. A thematic analysis was undertaken using NVIVO software.

\section{Findings}

This paper reports main findings under the themes of (1) Engaging Families and Service Users; (2) Managing Risk in Working with Families in Adult Safeguarding; and (3) Challenges for Professionals in Practice. A key finding was that professionals felt challenged personally and professionally in managing the risks and working with families in these highly complex cases.

\section{Originality and value}

Investigative approaches have their limitations in relation to adult abuse situations. This study adds to the existing knowledge base, identifies potential practice developments and discusses the challenges in adopting restorative approaches with families in elder abuse cases. The study highlights the need for further specialist training. Managers should consider the creation of specialist teams with a focus on alternative or restorative approaches with families.

\section{Keywords}

Adult protection; adult safeguarding; elder abuse; family care conferences; family group conferences; family mediation; family work; focus groups; managing risk; qualitative research; social work. 


\section{Classification: Research paper}

\section{Introduction}

The complex structure of families requires flexible, empowering, person-centred approaches in order to safeguard older people most effectively. Punishing offenders (who may often be family members with caring roles) may be detrimental to the care of the older person. Restorative approaches are seen as a more constructive social alternative to punitive systems in some situations of abusive relationships with older people. The aim of restorative justice approaches is to restore or recreate the relationship between the offender and the victim (Church Council on Justice and Corrections, 1996). By enabling victims to 'tell their story', the intention is to reconcile offenders and rebuild social relationships (Groh \& Linden, 2011). Varieties of restorative approaches, - such as Family Group Conferences (FGC), Family Care Conferences (FCC) and Family Mediation (FM) - are emerging as complementary or potential alternatives to formal processes. These place significant value on building capacity and resilience within families by working in partnership to identify realistic and achievable options in situations where abuse has occurred. In some instances this abuse may have been perpetrated by a close family member who will continue to play an on-going role in the older person's life. Following a brief literature review on the topic, this paper presents the findings of a study on professional perspectives on family-based restorative approaches to elder abuse.

\section{Brief Literature Review}

A systematic narrative review of three bibliographic databases, Psyclnfo, Social Care Online and Social Services Abstracts identified nine peer reviewed studies relating to family-centred work with older people who have experienced abuse. The themes of prevention, protection and partnership (Northern Ireland Adult Safeguarding Partnership, 2015) were used to structure the synthesis of the literature. The concept of 'safeguarding' includes both preventing harm occuring, and protecting where harm has already occurred. The dimension of 'partnership' encompasses the engagement of the 'victim', family members and appropriate professionals in restorative approaches. Key messages from the literature relating to these three themes are considered in this brief literature review .

\section{Prevention}

Begley et al (2012) carried out a study which looked at older people's views of support services in response to elder abuse in communities across Ireland. Participants highlighted how society should look beyond the somewhat inflexible boundaries within which the public health and social care services operate, and should consider alternative ways to support older people to retain their independence, remain connected within their communities, maintain and develop friendships and build the self-confidence to protect themselves. Begley et al. (2012) conclude that older people identified community development approaches as being crucial in supporting them to develop or maintain friendships, establish links within their communities and maintain their independence.

Lishman (2007) highlights the importance of seeing the individual as part of a broader 'family' system, which is particularly important in the arena of prevention as this may be the network of people who provide support, advice and guidance in relation to keeping safe and making good decisions. A study on elder abuse interventions by Holkup et al. (2007) with tribal communities in North America centred around a five-year, community-based participatory research project and investigated Family Care Conferences (FCC). The findings suggest that these approaches were generally appreciated as they build on the strengths of families, empowering and supporting them rather than merely highlighting abusive acts. 
Manthorpe et al. (2014) highlighted the danger of focusing on adult safeguarding process and outputs rather than the people being safeguarded and their experience. O'Donnell et al. (2014) acknowledge a shift, in line with other European countries, towards ending abuse and restoring relationships rather than focusing on punishment of perpetrators. This aligns particularly with the social work role in such situations. The findings of this study highlight the need to support existing relationships with family members and the wider community, and to adopt individualised case management approaches rather than applying a rigid protocol. O'Donnell (2014) concludes that social workers see the importance of protecting existing family relationships even when those relationships may be a source of risk to the service user. Effective family work in this context is crucial in ensuring risks are discussed and addressed through the development of an individualised protection plan.

Holkup et al. (2007) cautioned against the criminalisation of elder mistreatment as this approach does not recognise the context of the caring relationship. They stressed the importance of involving the family in protective measures whilst working together to solve problems. The Family Care Conference which was trialled with 10 families in the North American tribal community demonstrated that it helped to bring focus to concerns and align various family members' perspectives towards positive action in the 'here and now' rather than focusing merely on the problems. This broader societal role in protection is illustrated by McGarry et al (2014) who highlighted three key themes: (a) a lack of clarity in relation to the differences between adult safeguarding and domestic violence; (b) the complexity of family dynamics and abusive relationships; and (c) the lack of services for older adults who have been victims of domestic abuse.

\section{Partnership}

Various authors have emphasised that partnership in the context of adult safeguarding work with older people should begin with the individual, recognising the strengths and insights that they have (Killick et al, 2015; Tapper, 2010; Healy, 2014; O'Donnell et al, 2014). Metze et al. (2015b) found that strong partnership arrangements appear to provide a basis for successful interventions resulting in positive outcomes for service users. Partnership working and restorative approaches with families is are underdeveloped aspect of current adult safeguarding policies and procedures.

\section{Methods}

Few formal restorative interventions exist within Northern Ireland, but safeguarding practice often seeks to engage families and wider social structures. As little is known about these approaches this study sought to explore the understanding and perspectives of practitioners on a variety of family approaches. Focus groups were used as a means of gathering perceptions and capturing a body of practice knowledge. Enell and Schutt (2013) describe focus groups as a means of stimulating spontaneity of expression and social interaction. Focus groups have the advantage of using discussion as a means of eliciting different perspectives, opinions and motivations (Krueger and Casey, 2000). Focus groups are were held in existing teams, so that participants should feel comfortable discussing this servicedevelopment topic in the context of existing working relationships.

\section{The Sample}

The study was based in the Northern Health and Social Care Trust (NHSCT), the body that provides statutory health and social care services to a population of about 440,000 people in Northern Ireland. The population from which respondents were drawn was primarily the approximately 240 registered social workers within adult services teams, which provide field social work services to support hospital discharge; provision of community care services (including home care, day support and respite services); and admissions to residential and nursing home care. The study sample also included the local Women's Aid voluntary organisation which supports women in situations of domestic violence. The potential respondent group had extensive experience in the safeguarding of older people. In addition, 
they understood the complexity of family working and restorative approaches. Participants were recruited through meeting with line managers and eight focus groups were arranged incorporating a total of 37 professionally qualified staff.

An aide-mémoire was developed based on the literature review (Campbell et al 2016) which included open ended questions on the following themes:

- current experiences of adult safeguarding work with families;

- views and awareness of current or alternative approaches;

- new ideas or concepts for working with families in adult safeguarding; and

- anticipated challenges in introducing restorative approaches.

This was used to promote a focus on core themes without detracting from the group discussion. The process was piloted with social work learning and development officers who had experience in older people's services.

Eight focus groups were held May to July 2017. To ensure that the study drew on a range of experience, the focus groups were: two in the Community Care Division (older people and physical disability); one with Hospital Social workers; one in the team for Adult Safeguarding and Family Group Conferencing; one group from the teams for Mental Health of Older People; one group from Adult Learning Disability teams; and two groups of social workers in Women's Aid. Initial approval to approach staff was gained from the relevant Directors within both organisations and on-site meetings were arranged to coincide (where possible) with team meetings which were already in place. Ethical approval was granted by the Northern Health and Social Care Trust Research Governance Committee and by Ulster University School of Applied Social and Policy Sciences Research Governance Filter Committee. Written and verbal consent was gained from participants prior to and on the day of each focus group.

Thematic analysis was used to distil from transcripts common topics and understanding. NVivo software was used to manage the large volume of data, and to create and develop codes and themes. To improve rigour and minimise the risk of bias a colleague assisted with coding the information, initial differences in coding being discussed to reach consensus. Whilst saturation levels were not achieved across all areas, in the final focus groups similar messages were being heard as in previous groups, with few new ideas being voiced.

\section{Findings}

A total of 37 registered social workers employed by the Northern Health and Social Care Trust (NHSCT) or by Women's Aid participated in the focus groups. Of the 37 who attended approximately 12 had qualified within the last 5 years; 12 within the last 10 years; 12 within the last 15 years; and one person had over 15 years experience. The geographical spread of participants spanned the Trust area with teams from both rural and urban locations.

\section{Theme 1: Engaging families and service users}

The issue of engaging families and service users in the social work process was highlighted as important. Emphasis was also placed on exploring options, collaborative working and emotional impact of the safeguarding process. Engagement with service users was viewed as a crucial step in managing risk in safeguarding situations. One worker described a case where elderly brothers each with a diagnosis of learning disability were living in unhygienic conditions and appeared to be having difficulty in managing their finances. Their family, when alerted, claimed to have been unaware of their deteriorating circumstances. The social worker explained that by "...... bringing the family in and having the discussion and asking them, what you can do?" it was possible to achieve a positive outcome for everyone (Group 1). In this instance there was engagement and participation, although other examples were shared of family members challenging professional assessments; ignoring risk management guidance; and at times appearing to contribute to or cause the abuse or neglect. 
Social workers indicated that individuals and their family members were often involved in assessment, risk assessment, case conferences, reviews and decision making from the outset. Approaches such as Family Group Decision Making and discussion at support hubs were mentioned by two of the groups. The Group members described an increasing need for 'best interests' meetings to find resolution in cases where capacity is in question and there is risk. One participant stated that restorative approaches, although not currently available would be welcomed as a quicker way of resolving issues (Group 6).

Groups highlighted the added value and challenges in collaborative working. Joint visits with the police, and other professionals were cited as positive examples of partnership working (Group 2). Differing opinions on risks and rights between professionals (including social workers, doctors, nurses and occupational therapists) were cited as being frustrating. One social worker highlighted the need for all professionals to be trained on the same processes to promote a shared understanding and responsibility in relation to risk management and safeguarding: "Lots of the training we go to is profession-based and I believe that it should be opened up to colleagues [from other professions]" (Group 6).

The emotional impact of abuse or neglect on individuals was seen as potentially devastating. Social workers recognised the importance of restorative approaches in these situations and related their concerns around the challenges of advocating for service users and ensuring their voice was heard. This may be challenging in certain situations where family members present as assertive, forceful or aggressive. One social worker stated that, "It's interesting when the family become the people you are most concerned about in someone's life" (Group 7). Participants gave examples of the impact coercive control can have on the victim: "...... her self-worth is nil from what he tells her and how he treats her" (Group 7). A key challenge for professionals is to help people recognise abuse and its unacceptability.

\section{Theme 2: Managing risk in working with families in adult safeguarding}

Professionals highlighted the complex risk factors which influence decision making; families' views on risks; and the complexity of decisional capacity and moral rights issues. The types of risk mentioned included non-compliance with professional recommendations, and complex relationships between families and professionals which if unaddressed, could result in physical or psychological harm. There were concerns regarding accountability, using professional judgement in risk situations, and having a clear legislative mandate.

Many of the participants highlighted complex relationships between family members as a catalyst for increased risk or danger. Conflict within families, mental health problems, cultural influences and distinguishing between pre-meditated deliberate abuse versus the lack of skills, knowledge or awareness were identified as key challenges. Overall there was a sense of frustration with the limitations of legislative powers coupled with an awareness of human rights. One group participant highlighted "The difficulty for us sometimes, in terms of safety measures, we can't control what people do and it's their choice to go back into or remain in relationships where they are completely exposed to high levels of risk of domestic violence whether its physical or sexual, in our position we can only support them as they make their choices" (Group 4). Supporting people to make choices which professionals may not agree with was regarded as a central issue in relation to both safeguarding and managing risks. One worker stated that it was the social workers' tenacity and commitment to their role in securing positive outcomes for their service users that makes the most difference (Group 5).

Within every situation of concern the individual is at the centre. However social workers recognised the crucial role the family play in prevention and protection, and at times in facilitating or perpetrating the abuse. One group explained how in the case of an older female victim of domestic violence, her adult children convinced her to remain with their father even though she was being subjected to abuse on a daily basis (Group 4). This appeared to be a cultural issue within a close-knit farming community coupled with a lack of insight in relation to the potential risks and impact of this on-going violence on their mother, particularly as she was older and becoming frail.

The challenges when a person did not have decisional capacity were highlighted in most group sessions, particularly when family members misunderstood or misused their 
power in relation to decisions on behalf of the individual. The need for more active approaches to engaging families highlighted issues of contention in balancing professional responsibilities with seeking an enabling, problem-solving approach. Some social workers carried out mental capacity assessments within their professional remit. This had alleviated some of the concerns of their colleagues who were reliant on other professionals to undertake this role.

\section{Theme 3: Challenges for professionals in practice}

Respondents felt that partnership working required time and commitment, and that it was most effective when used in a pro-active rather than a reactionary manner. One participant stressed the need to consider Family Group Conferencing during the early stages of intervention rather than waiting for a crisis. Another gave an example of how Family Group Decision Making has been used to good effect in situations where there is one time-limited decision to be made. It was noted that there were many challenges for professionals on issues such as managing the emotional impact of dealing with complex cases; understanding cultural perspectives; frustrations with limited legislative powers; and dealing with difficult family dynamics and interdependencies.

Participants considered the potential challenges to restorative approaches with families in elder abuse cases. A strong sense of the need for specially-trained staff with a focus on this area of work was voiced often. One example given was that the social worker undertaking case management for the individual might be too close to the issue, and a different person undertaking the family work might be more effective (Group 3). Others talked about becoming involved at times of crises and how this may impact on the effectiveness of restorative work. Lack of time and resources were mentioned by a number of participants but there was a keen interest and positive feedback from those who had previously experienced the benefits of Family Group Conferencing or similar models in child care services. One social worker stated that "....you will find if your restorative approach will work or not because if the family members are not willing to engage or work towards a goal and aims then it's not going to be restorative" (Group 6). Concerns were voiced around how much 'buy in' there would be from families and individuals as there is no legislative requirement for them to do so, unlike within children's services (Group 6). Others cautioned that careful consideration would need to be given regarding involving those who were potential perpetrators, and warned that it would not be appropriate in every case (Groups 4 \& 8). Issues around the capacity of the service user to make decisions could impact on the effectiveness of this type of model as well.

Cultural issues raised were, for example: "including families in the whole journey which isn't always easy especially in the current culture where people are out working all day" (Group 6). Another described a case where the service user informed them that: "I didn't know that that wasn't normal; I thought everyone had to go through that" (Group 4). One discussion on cultural perspectives centred around female victims of domestic abuse within the travelling community who find it difficult to leave or change their situation (Group 3). Another group highlighted other professions failing to respond appropriately to allegations of abuse and not understanding their role in recognising and reporting. In relation to domestic violence one worker stated that: "there is no class involved, this happens everywhere and to anyone" (Group 4). There were discussions regarding the over-protection of service users with learning disabilities, and how there have been moves towards more person-centred practice. Some explained how they no longer automatically go to the family if something has happened. Instead they start with the person, asking what they want and trying to do their best to honour that ( Group 9).

Inter-dependencies in families is a strong thread running through a number of themes, but it is important to recognise this issue in its own right. Professionals understood and in some cases advocated for restorative approaches to protect and rebuild relationships damaged by abuse or neglect. There was recognition that whilst risk or uncertainty may remain, in some situations service users value relationships above their own welfare. As such they recognised their duty to empower and protect these individuals as far as their professional remit allowed. Examples of counterproductive or 'toxic' relationships were discussed. In one group a social worker explained that families can be extremely 'risk averse' and unwilling to 
consider alternative views or recommendations from professionals. The range from overprotective care to deliberate abuse and neglect demands a variety of skills and knowledge, and challenges even experienced workers.

Social workers emphasised their commitment to finding the best alternative care and safeguarding for their service users and described the challenges in balancing between managing risk and empowering. One example given was a case where the family, with the best intentions, campaigned to have an older relative returned from a group care environment (where she had settled very well) to her own home where she lived alone. As a result of returning home and being looked after by a range of different services and supports, she became more confused and withdrawn (Group7).

\section{Discussion}

In terms of limitations, it is recognised that this study focused on one geographical area where few formal restorative interventions had been implemented. However, this study provides a valuable insight into the use of restorative approaches with family within adult safeguarding processes in Northern Ireland. Respondents were amongst the most (rather than typically) knowledgeable on the topic within the geographical area of one Health and Social Care Trust that covers about a quarter of the population of Northern Ireland, and which includes both urban and rural areas. It is recognised that other countries will have different legislation and service configurations (Montgomery and McKee, 2017). However, as the focus of the study was on methods of intervention with families, this study should have relevance in other jurisdictions and service providers.

A crucial element of successful restorative interventions with service users and their families is effective engagement (Fengler \& Taylor, 2019; Mantell and Scragg, 2009; Stevenson \& Taylor, 2016; Taylor \& Mckeown, 2013) and partnership working (Frey 2006). Within all the focus groups there was recognition of the emotional impact of safeguarding situations on the service users and their families. There was an understanding of the complex family dynamics and undercurrents within relationships, as in other aspects of social work (Stevenson \& Taylor, 2017). Challenges in managing carer stress, complex relationships, addictions, mental health and domestic violence were cited as examples of the additional difficulties encountered when working with families as well as individuals. Johnson and Slater (1993) acknowledge factors such as ageism, family discord and psychopathology which when coupled with situational stress may create circumstances where abuse is more likely to occur. The literature suggests that interventions need to empower the individual whilst also recognising the unique and complex contribution of families and communities in relation to the person at risk (Metze et al., 2015a; Holkup et al., 2007; O'Donnell 2014). The roles, remit and approaches currently adopted by the Trust and Women's Aid differed but shared a common foundation concerning risk management and it could be concluded that there is much to learn from each other in terms of sharing positive experiences and challenges. It was recognised, however, that in general a family approach had potential for longer-term benefit for all involved compared to investigative procedures that became, at times, contentious.

In some cases, it was recognised that Family Group Conferencing may not be the best option for the service user and others involved. Examples cited were around domestic violence cases or where the main carer was the suspected perpetrator. In contrast there were suggestions that rather than using restorative practice in cases which have reached crisis point, it could or should be considered at an earlier stage as a preventative measure. This is in line with McGarry et al. (2014) who suggest that the nature of the social networks which surround the individual may play a significant part in the success of interventions.

There were many challenges for professionals in practice, not least being the emotional impact of the work on them (Collins 2008). A lack of clarity around statutory powers and having to work within a complex range of statutes rather than one piece of robust legislation appeared to leave social workers in adult services frustrated and at times discouraged (Commissioner for Older People Northern Ireland, 2014; Anand et al 2013). Overall, however, there was an understanding of the gravity of the work, and a sense of pride in cases where positive 
outcomes had been achieved. Reflections and discussions around cases where there had been less favourable results achieved were cited as being useful learning opportunities (Houston, 2015; McFadden, 2015).

Participants appeared to have a good understanding of different types of abuse and of signs and symptoms. Participants most frequently provided examples of physical abuse and domestic violence. Staff highlighted financial abuse as a substantial issue confirming concerns in a recent report by the Commissioner for Older People Northern Ireland (2016). The categories of abuse least talked about were exploitation and institutional abuse. Neglect and emotional abuse were discussed with a number of examples cited; sexual abuse was also considered with four examples being given in the focus group sessions. McGarry et al. (2014) highlight the lack of clarity around the distinction between domestic violence and abuse. This issue is also raised by Mantell and Scragg (2009) who argue that the way we categorise situations can have an impact on our responses. Interestingly there were no references to managing risk where social care is provided through publicly-funded personal budgets despite messages from research in the UK regarding this recently-recognised risk (Ismail et al., 2017).

The complexity of risk when there are multiple family members involved gives an added dimension to models of social care that focus on individual adults (Taylor 2006; Taylor 2011). The assessment and management of risk where there are multiple actors requires an increased sophistication to our models of assessment, decision making and care planning (Killick and Taylor 2009; Taylor, 2012a\&b; Taylor 2017a\&b). The rights of families as well as of individuals must be balanced with professional accountability for managing risk and the expectations of society (Taylor \& Campbell, 2011).

Challenges noted by staff in dealing with the different types of situations appeared to be exacerbated by the fact that individuals do not always recognise that they are being abused. Professionals played a role in educating and empowering victims of abuse (O'Donnell 2014; McGarry et al., 2014). They also highlighted consent and capacity issues where the service user's capacity to make decisions is in question, but the person continues to expose themselves to harm or risk of harm.

Given the challenging nature of safeguarding work, the knowledge, skills and values of the social work staff tasked with the role is key to its success. Focus group members felt there was a need for specially trained, independent staff who are not involved directly with the case to take the lead. This echoes the comments of Bagshaw et al. (2015) in their mixed methods study of elder mediation in cases of financial abuse where they highlighted the importance of facilitators having specialist knowledge and skills to achieve positive outcomes.

A reliance on protective responses has the potential to undermine prevention and harm reduction (Manthorpe et al., 2008). Professionals tasked with a safeguarding role need flexible, empowering person-centred approaches to complement more formal processes. Balancing rights against risks can be a challenge for professionals (O'Donnell et al., 2014), sometimes considered operationally as balancing individual circumstances with following procedures (McGarry et al., 2014). The role of the professional in weighing-up information and forming a judgement was seen as central (Killick \& Taylor, 2012). This may involve weighing up the demands of 'risk averse' family members and professionals with those who tolerate a higher level of risk (Taylor, 2011).

With the complexity of the adult safeguarding role, specialist post-qualifying training for social workers is required to build on the generic knowledge and interpersonal skills provided in qualifying training. In addition to therapeutic skills in working with families, generic skills in decision making and in the management of risk need to be developed at specialist level if family work in adult safeguarding is to be most effective in safeguarding vulnerable clients and restoring a measure of family functioning. In order to further develop family approaches to elder abuse, professionals need to develop skills to facilitative the distinctive 'telling my story' dimension of restorative justice approaches.

\section{Conclusions}


Restorative approaches present challenges in a risk-averse society. This study highlighted the increased complexity when working with families in elder abuse cases, rather than focusing on the individual who is deemed to be at risk. Preventative and partnership approaches were seen to be essential, but staff thought that this required specialist training to be most effective. An essential component of successful restorative approaches is the ability and willingness of the older person and of the family members to engage in rebuilding family relationships. Specialist training and more sophisticated approaches to assessment are required to appraise the potential for effective intervention within complex family dynamics and to carry these out effectively.

\section{Originality and Value}

The following key messages help to clarify professional experience in relation to this complex form of intervention.

- Professionals regarded restorative family approaches in situations of elder abuse as having potential as well as presenting challenges.

- Restorative approaches are particularly challenging in a risk-averse society.

- Working with the complexity of family members and their relationships requires a high level of reflective, professional practice.

- Although basic social work skills were very relevant to the work, specialist skills were regarded as essential for effective outcomes.

\section{Acknowledgements}

The authors are grateful to the management and staff of the Northern Health and Social Care Trust and Women's Aid (County Antrim, NI) who supported this project and would like to extend particular thanks to the participants from both organisations who took part in the focus groups.

\section{References}

Anand, J.C., Begley, E., O'Brien, M., Taylor, B.J. \& Killick, C. (2013). Conceptualising elder abuse across local and global contexts: implications for policy and professional practice on the island of Ireland. The Journal of Adult Protection, 15(6), 280-289. doi:10.1108/JAP-032013-0011

Bagshaw, D., Adams, V., Zannettino, L., \& Wendt, S. (2015). Elder Mediation and the Financial Abuse of Older People by a Family Member. Conflict Resolution Quarterly, 32(4), 443-480. http://dx.doi.org/10.1002/crq.21117

Baker, P., Francis, D., Mohd Hairi, N., Othman, S., \& Choo, W. (2016). Interventions for preventing elder abuse: applying findings of a new Cochrane review. Age And Ageing. http://dx.doi.org/10.1093/ageing/afw186

Begley, E., O'Brien, M., Carter Anand, J., Killick, C., \& Taylor, B. (2012). Older people's views of support services in response to elder abuse in communities across Ireland. Quality In Ageing And Older Adults, 13(1), 48-59. http://dx.doi.org/10.1108/14717791211213616

Boyatzis, R. (1998). Transforming Qualitative Information: Thematic Analysis and Code Development. Thousand Oaks, CA: Sage Publications.

Campbell A, Taylor BJ \& McGlade A (2016) Research Design in Social Work: Qualitative and Quantitative Methods. London: Sage

Church Council on Justice and Corrections (1996). Satisfying justice. Ottawa, ON: author.

Commissioner for Older People Northern Ireland. (2016). Financial Abuse of Older People in Northern Ireland. Belfast: author.

Department of Health, Social Services and Public Safety, Northern Ireland. (2011). Transforming your Care. Belfast: author. 
Department of Justice, Northern Ireland. (2012). Achieving Best Evidence in Criminal Proceedings. Belfast: author.

Devaney, J., Bunting, L., Hayes, D., \& Lazenbatt, A. (2013). Translating Learning into Action. Belfast: Queen's University Belfast.

Fengler J \& Taylor BJ (2019) Effective assessment: a key knowledge and skill for a sustainable profession. Social Work Education: The International Journal, 38(3), 392-405. doi:10.1080/02615479.2018.1538333

Frey, B., Lohmeier, J., Lee, S., \& Tollefson, N. (2006). Measuring Collaboration Among Grant Partners. American Journal of Evaluation, 27(3), 383-392. http://dx.doi.org/10.1177/1098214006290356

Arlene Groh BA RN \& Rick Linden PhD (2011) Addressing Elder Abuse: The Waterloo Restorative Justice Approach to Elder Abuse Project Journal of Elder Abuse \& Neglect, 23(2), 127-146. DOI: 10.1080/08946566.2011.558780.

Health and Social Care Board Northern Ireland. (2016). Protocol for Joint Investigation of Adult Safeguarding Cases. Belfast: author.

Healy, K., (2014). Social Work Theories in Context. London; Palgrave Macmillan.

Holkup, P., Salois, E., Tripp-Reimer, T., \& Weinert, C. (2007). Drawing on Wisdom From the Past: An Elder Abuse Intervention With Tribal Communities. The Gerontologist, 47(2), 248254. http://dx.doi.org/10.1093/geront/47.2.248

Houston, S., Reflective Practice: A Model for Supervision and Practice in Social Work; Northern Ireland Social Care Council. Belfast:DoH.

Ismail, M., Hussein, S., Stevens, M., Woolam, J., Manthorpe, J., Aspinal, F., Baxter, K., \& Samsi, K. (2017). Do personal budgets increase the risk of abuse? Evidence from English national data. Journal of Social Policy, 46(2): 291-311.

Killick, C. \& Taylor, B.J. (2009). Professional decision making on elder abuse: systematic narrative review. Journal of Elder Abuse and Neglect, 21, 211-238. doi:10.1080/08946560902997421Mantell, A., \& Scragg, T. (2011). Safeguarding Adults in Social Work. Exeter: Sage.

Killick, C. \& Taylor, B.J. (2012). Judgments of social care professionals on elder abuse referrals: a factorial survey. British Journal of Social Work, 42(5), 814-832. doi:10.1093/bjsw/bcr109

Killick, C., Taylor, B.J., Begley, E., Anand, J.C. \& O’Brien, M. (2015). Older people's conceptualization of abuse: a systematic narrative review. Journal of Elder Abuse and Neglect, 27(2), 100-120. doi:10.1080/08946566.2014.997374

Manthorpe, J., Stevens, M., Rapaport, J., Harris, J., Jacobs, S., Challis, D., ... \& Glendinning, C. (2008). Safeguarding and system change: Early perceptions of the implications for adult protection services of the English individual budgets pilots-a qualitative study. British Journal of Social Work, 39(8), 1465-1480.

Manthorpe, J., Klee, D., Williams, C., \& Cooper, A. (2014). Making safeguarding personal: developing responses and enhancing skills. The Journal Of Adult Protection, 16(2), 96-103. http://dx.doi.org/10.1108/jap-07-2013-0027

Mason, P., Barnes, M., \& Morris, K. (2009). Children, families and social exclusion: New approaches to prevention. Bristol: Policy Press.

McFadden, P. (2015) Measuring burnout among UK social workers: a community care study. Available from: http://www.pub.ac.uk/home/media/Media,514081,en.pdf [Accessed $13^{\text {th }}$ September 2017]

McGarry, J., Simpson, C., \& Hinsliff-Smith, K. (2014). An exploration of service responses to domestic abuse among older people: findings from one region of the UK. The Journal Of Adult Protection, 16(4), 202-212. http://dx.doi.org/10.1108/jap-08-2013-0036

Metze, R., Kwekkeboom, R., \& Abma, T. (2015a). You don't show everyone your weakness: older adults' views on using family group conferencigg to regain control and autonomy. Journal Of Aging Studies, 34, 57-67. http://dx.doi.org/10.1016/j.jaging.2015.04.003

Metze, R., Kwekkeboom, R., \& Abma, T. (2015b). The potential of family group conferencing for the resilience and relational autonomy of older adults. Journal Of Aging Studies, 34, 68-81. http://dx.doi.org/10.1016/j.jaging.2015.04.005 
Montgomery, L. and McKee, J. (2017). Adult safeguarding in Northern Ireland: prevention, protection, partnership. The Journal of Adult Protection, 19(4), 199-208.

Northern Ireland Adult Safeguarding Partnership. (2013). Training Strategy and Framework, 2013-2016. Belfast: author.

Northern Ireland Adult Safeguarding Partnership. (2015). Adult Safeguarding: Prevention and Protection in Partnership. Belfast: author.

Northern Ireland Adult Safeguarding Partnership. (2016). Adult Safeguarding Operational Procedures. Belfast: author.

Northern Ireland Social Care Council. (2015). Reflective Practice: a Model for Supervision and Practice in Social Work. Belfast: author.

O'Donnell, D., Treacy, M., Fealy, G., Lyons, I., \& Lafferty, A. (2014). The case management approach to protecting older people from abuse and mistreatment: lessons from the Irish experience. British Journal of Social Work, 45(5), 1451-1468. http://dx.doi.org/10.1093/bjsw/bcu027

Stevenson, M. \& Taylor, B.J. (2016). Risk communication in dementia care: family perspectives. Journal of Risk Research, 18(1-2), 1-20. doi:10.1080/13669877.2016.1235604

Stevenson, M. \& Taylor, B.J. (2017). Risk communication in dementia care: professional perspectives on consequences, likelihood, words and numbers. British Journal of Social Work, 47(7), 1940-1958. doi:10.1093/bjsw/bcw161

Tapper, L. (2010). Using family group conferences in safeguarding adults. The Journal Of Adult Protection, 12(1), 27-31. http://dx.doi.org/10.5042/jap.2010.0091

Taylor, B.J. (2006). Risk management paradigms in health and social services for professional decision making on the long-term care of older people. British Journal of Social Work, 36(8), 1411-1429. doi:10.1093/bjsw/bch406

Taylor, B.J. (Ed.) (2011). Working with Aggression and Resistance in Social Work. London: Sage.

Taylor, B.J. (2012a). Models for professional judgement in social work. European Journal of Social Work, 15(4), 546-562. doi:10.1080/13691457.2012.702310

Taylor, B.J. (2012b). Developing an integrated assessment tool for the health and social care of older people. British Journal of Social Work, 42(7), 1293-1314. doi:10.1093/bjsw/bcr133

Taylor, B.J. (2017a). Decision Making, Assessment and Risk in Social Work ( $3^{\text {rd }}$ ed). London: Sage.

Taylor, B.J. (2017b). Heuristics in professional judgement: a psycho-social rationality model. British Journal of Social Work, 47(4), 1043-1060. doi:10.1093/bjsw/bcw084

Taylor, B.J. \& Campbell, B. (2011). Quality, risk and governance: Social Workers' perspectives. International Journal of Leadership in Public Services [NOW the International Journal of Public Leadership], 7(4), 256-272. doi:10.1108/17479881111194152

Taylor, B.J., Killick, C., O'Brien, M., Begley, E. \& Carter-Anand, J. (2014). Older people's conceptualisation of elder abuse and neglect. Journal of Elder Abuse and Neglect, 26(3), 223243. doi:10.1080/08946566.2013.795881

Taylor, B.J. \& McKeown, C. (2013). Assessing and managing risk with people with physical disabilities: development of a safety checklist. Health, Risk and Society, 15(2), 162-175. doi:10.1080/13698575.2013.764973 